\title{
СЕМАНТИЧЕСКИЕ ЭТЮАЬ
}

DOI 10.15826/izv2.2018.20.3.049

Н. А. Баева

УДК 821.111-31 + 811.111’'42

А. А. Фомин

Кемеровский государственный университет

Кемерово, Россия

\section{МОДЕЛИ СИНЕСТЕТИЧЕСКИХ СОЧЕТАНИЙ СЛОВ И ИХ МАРКИРОВАННОСТЬ (на материале романов Терри Пратчетта)}

\begin{abstract}
Статья посвящена исследованию феномена синестезии с позиции когнитивного подхода. Рассматриваются вербализованные синестетические ощущения, которые сочетают в себе обычное ощущение совместно с другим, дополнительным ощущением, не связанным напрямую с органом, продуцирующим это ощущение. Методология исследования основывается на применении одного из параметров когнитивной лингвистики - маркированности / немаркированности - при анализе синестетических сочетаний слов как стилистического приема художественной речи. Материалом для анализа выступают тексты романов жанра фэнтези современного английского писателя Терри Пратчетта “The Colour of Magic” («Цвет волшебства»), “Going Postal” («Держи марку»), “Making Money” («Делай деньги»), "Raising Steam” («Поддай пару»), “The Wee Free Men” («Вольные мальцы»), “Wintersmith” («Зимних дел мастер»), "I Shall Wear Midnight” («Я надену платье цвета ночи»), в которых репрезентация синестезии в виде разнообразных синестетических словосочетаний является стилистической авторской доминантой. В центре внимания статьи находятся синестетические сочетания слов, коррелирующие с пятью органами восприятия (зрение, слух, обоняние, вкус, осязание), анализируемые с точки зрения сенсорной дистанции между модусами перцепции (высшая / низшая сфера сенсориума), информативности (простота / сложность контекстуальных пояснений), а также семантической емкости (узуальности / окказиональности). Авторами выделяются структурносемантические модели синестетических сочетаний и делается вывод о различной степени когнитивной маркированности таких сочетаний, связанной со степенью отдаленности модусов перцепции синестетических сочетаний, с закрепленностью
\end{abstract}

(C) Баева Н. А., Фомин А. А., 2018

Известия УрФУ. Серия 2. Гуманитарные науки. 2018. Т. 20. № 3 (178) 
таких сочетаний в словарном составе английского языка и с контекстуальными пояснениями и уточнениями автора. Проделанное исследование позволяет прийти к выводу о том, что когнитивный параметр маркированности / немаркированности является релевантным для феномена синестезии; применение параметра когнитивной маркированности позволило выявить четыре типа моделей синестетических сочетаний в текстах Пратчетта в зависимости от степени их когнитивной маркированности.

К л ю ч е в ы е с л о в а: синестезия; синестетические сочетания слов; модусы перцепции; когнитивный подход; маркированность; немаркированность; контекст.

Ц и т и р о в а н и е: Баева Н. А., Фомин А. А. Модели синестетических сочетаний слов и их маркированность (на материале романов Терри Пратчетта) // Изв. Урал. федер. ун-та. Сер. 2 : Гуманитар. науки. 2018. Т. 20. № 3 (178). С. 110-124.

Поступила в редакцию 07.12.2016

Принята к печати 21.06.2018

Natalia A. Baeva

Anatoly A. Fomin

Kemerovo State University

Kemerovo, Russia

\section{MODELS OF SYNAESTHETIC WORD COMBINATIONS AND THEIR MARKEDNESS (with Reference to Terry Pratchett's Novels)}

This article studies the theory of synaesthesia from the perspective of the cognitive approach. The authors analyse verbalised synaesthetic sensations (combining usual sensation accompanied by additional involuntary sensation produced by another organ of perception). The methodology of the research is based on the cognitive analysis of synaesthetic word combinations as a stylistic device in a literary text with the application of a cognitive parameter - markedness / unmarkedness. The analysis is conducted with reference to The Colour of Magic, Going Postal, Making Money, Raising Steam, The Wee Free Men, Wintersmith, and I Shall Wear Midnight by Terry Pratchett, in which synaesthesia represented by synesthetic word combinations is a dominant stylistic feature of the author. The paper focuses on synaesthetic word combinations with reference to the senses of sight, sound, smell, taste, and touch. Synaesthetic word combinations are analysed from the point of view of sensory distance between perception modes (higher / lower sphere of the sensorium), the information value (simplicity / complexity of contextual explanations) and semantic capacity (usage / occasionality) of synaesthetic word combinations. The authors of the paper distinguish structuralsemantic models of synaesthetic word combinations and conclude that synaesthetic word combinations demonstrate different levels of markedness, connected a) with the distance between perceptual modes, as well as b) with the representation of such combinations in the lexicon of the English language and c) with the surrounding 
context. The authors also conclude that cognitive markedness / unmarkedness is a relevant parameter for the analysis of synaesthesia. The application of the cognitive markedness parameter makes it possible to identify four types of models of synaesthetic word combinations in Pratchett's fantasy novels, depending on the degree of their cognitive markedness.

K e y w o r d s: synaesthesia; synaesthetic word combinations; perception modes; cognitive approach; markedness; unmarkedness; context.

C i t a t i o n: Baeva, N. A., \& Fomin, A. A. (2018). Modeli sinesteticheskikh sochetanij slov i ikh markirovannost' (na materiale romanov Terri Pratchetta) [Models of Synaesthetic Word Combinations and their Markedness (with Reference to Terry Pratchett's Novels)]. Izvestia. Ural Federal University Journal. Series 2: Humanities and Arts, 20, 3 (178), 110-124.

Submitted on 07 December, 2016 Accepted on 21 June, 2018

Интерес к явлению синестезии и ее вербализации проявляется исследователями разных областей научного знания и разных научных школ. Под сине-

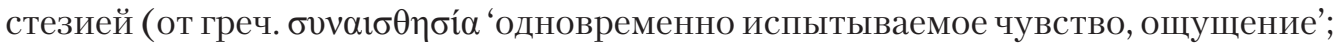
«соощущение») в психологии понимается явление, заключающееся в том, что какой-то раздражитель, воздействуя на один орган чувственного восприятия, непроизвольно вызывает не только ощущение, характерное для этого органа, но одновременно с этим и дополнительное ощущение, свойственное другому органу чувственного восприятия [Карпенко, с. 188].

Синестезия в лингвистике рассматривается как «слияние качеств различных сфер чувствительности, при котором качества одной модальности переносятся на другую» [Рубинштейн, с. 216]. Например, в языке встречаются такие выражения, как кричащий цвет, бархатистый голос. Синестетические сочетания слов требуют определенных усилий для их понимания. Как указывает А. Р. Лурия, «сочувствование, которое возникает как интермодальное смешение в нашем головном мозге, ведет к тому, что язык реагирует на него специфическими словосочетаниями» [Лурия, с. 134].

Синестезия является особым процессом восприятия и связана с перцептивной деятельностью человека. Перцептивность в лингвистике определяется как «наличие в семантике языковых единиц указания на определенную перцептивную модальность» [Лаврова, с. 49]. И. Г. Рузин дает подробное описание всех видов перцепции и их выражения в языке (зрительная, слуховая, обонятельная, тактильная, вкусовая) и распределяет их по так называемым модусам перцепции, при этом называя синестетические сочетания слов интермодальными сочетаниями [Рузин, с. 94].

Синестезия вербализуется в виде различных сочетаний слов и метафор. По словам Н. Д. Арутюновой, «особенности сенсорных механизмов и их взаимодействие с психикой позволяют человеку сопоставлять несопоставимое 
и соизмерять несоизмеримое. Это устройство действует постоянно, порождая метафору в любых видах дискурса» [Арутюнова, с. 5].

Следует отличать синестетические сочетания слов (синестетическую метафору в том числе) от метафоры перцептивной и метафоры не сенсорного характера. Как указывает Г. Цоллингер, в синестетической метафоре семантический сдвиг происходит в области ощущений; такой сдвиг отличен от сдвига, происходящего при обыкновенной метафоризации [Цоллингер, с. 168-171]. Перцептивная метафора основывается на одном модусе перцепции, в то время как синестетическая метафора предполагает использование двух и более модусов, показывая тем самым интермодальный характер переноса. Схожее мнение наблюдается в работе А. Х. Мерзляковой, которая называет метафоры, основанные на переносе с какого-либо признака на перцептивный признак, монорецепторными метафорами, а метафоры, в которых перенос осуществляется с перцептивного признака на перцептивный признак, - полирецепторными [Мерзлякова, с. 65].

В лингвистических исследованиях номинации синестетических ощущений рассматриваются в сопоставительном аспекте [Бардовская]; изучаются закономерности образования синестетических сочетаний слов [Кривенкова]; исследуются синестетические сочетания слов с точки зрения их принадлежности к частям речи [Капанова; Степанян; Яницкая], к модусам перцепции [Молодкина], к средствам выразительности и образности [Филиппова]. Многообразие имеющихся работ и подходов, посвященных исследованию синестезии, говорит о значительном интересе к теме исследования, однако в рамках когнитивной лингвистики, как нам кажется, явление синестезии остается малоизученным и требует дальнейшего научного осмысления. Мы рассмотрим явление синестезии с точки зрения структурно-семантических моделей синестетических сочетаний и их когнитивной маркированности, принимая при этом во внимание сенсорную дистанцию между модусами перцепции, объем контекстуальных уточнений, узуальность и окказиональность синестетических сочетаний.

Понятие маркированности изначально использовалось для характеристики звуков и применялось в фонологии. В частности, у Н. С. Трубецкого понятие маркированности применяется в теории фонологических оппозиций, в работах Р. Якобсона также присутствует характеристика маркированности / немаркированности, которая именуется автором признаковость / беспризнаковость [Кибрик, с. 205-207]. Дж. Гринберг расширяет строгую бинарную оппозицию маркированности / немаркированности, предлагая иерархию возрастания или убывания исследуемого параметра, что в результате получает следующий вид: немаркированный элемент / менее маркированный элемент / более маркированный элемент.

На степень маркированности языкового явления может оказывать влияние контекст. Как указывает Дж. Гринберг, «маркированность не является единственной и абсолютной характеристикой, часто маркированность соотносится с заданным контекстом» [Greenberg, p. 15]. Контекст, понимаемый 
как дополнительные, уточняющие характеристики описываемых процессов, явлений и их свойств, увеличивает степень маркированности, поскольку увеличивается количество информации об объекте, подвергающейся последующей мыслительной обработке.

По мнению А. Е. Кибрика, в рамках когнитивного подхода языковая маркированность будет являться производной от когнитивной маркированности, поскольку «когнитивный подход постулирует ее надъязыковую, когнитивную природу, не зависящую от структур конкретных языков» [Кибрик, с. 209]. В соответствии с этим, немаркированные языковые значения соответствуют когнитивному нормальному, т. е. ожидаемому положению дел, а маркированные языковые значения - когнитивно отклоняющемуся от нормы, несвойственному и неожидаемому положению дел. «Нормальное, естественное, ожидаемое положение вещей входит в когнитивный гештальт человеческого опыта и концептуализируется с минимальной затратой ментальных вычислительных усилий (активируется по умолчанию), а отклонения от гештальта для их активации требуют дополнительных вычислительных ресурсов» [Там же].

Когнитивная маркированность / немаркированность связана с контекстуальными особенностями [Greenberg, p. 15; Касавин, с. 383]. Обилие языкового или экстраситуационного контекста, свидетельствующее о высокой степени когнитивной маркированности, малое число контекстуальных пояснений, говорящее о низкой степени когнитивной маркированности, и отсутствие уточняющей информации, указывающее на когнитивную немаркированность, - это критерии определения иерархии маркированности. При этом ряд синестетических сочетаний слов может быть зафиксирован в словаре, другие возникают в языке под влиянием самых разнообразных факторов.

Перенос в синестетических сочетаниях в большинстве случаев осуществляется из низких сфер восприятия (сенсориума) - тактильной, вкусовой и ольфакторной (обонятельной) - в высокие сферы - слух и зрение. Несовместимость этих сфер, а также значительная сенсорная дистанция между ними позволяет говорить о высокой степени маркированности синестетических сочетаний с переносом значения из низких сфер сенсориума в высокие. В то же время, возможны случаи переноса значения в рамках высокой сферы сенсориума - из зрительной в слуховую или из слуховой в зрительную. Синестетические сочетания с таким типом переноса в основном лексикализованные, они не являются когнитивно маркированными. Таким образом, можно выделить следующую корреляцию типов переноса и когнитивной маркированности.

1. Перенос из низких сфер сенсориума в высокие или наоборот определяет высокую степень маркированности синестетических сочетаний. Например, перенос из низких сфер в высокие: а) тактильный $\rightarrow$ слуховой (241 сочетание, 36,4 \%): "they darted away into the freezing silence" («они бросили взгляд на замораживаюшую тишину») [Pratchett, 2013b]; б) тактильный $\rightarrow$ зрительный (64 сочетания, 9,6\%): “cold blue light” («холодныцй синий свет») [Pratchett, 2006]; в) вкусовой $\rightarrow$ слуховой (31 сочетание, 4,65 \%): “said Rincewind sourly" («сказал 
горько Ринсвинд») [Pratchett, 2013b]; г) вкусовой $\rightarrow$ зрительный (2 сочетания, 0,35 \%): "There was darkness everywhere, bitter and starless" («Вокруг была темнота, горькая и беззвездная») [Pratchett, 2003]; д) ольфакторный $\rightarrow$ слуховой (4 сочетания, 0,6 \%): "it sounded like the smell of raspberries" («әто звучало как запах малинь») [Pratchett, 2007], "stinking voice" («вонючий голос») [Pratchett, 2010]; е) ольфакторный $\rightarrow$ зрительный (2 сочетания, 0,35 \%): “a light that even smelled" («свет, который даже имел запах») [Pratchett, 2003], "pigeon-smelling gloom" («пахнущая голубями темнота») [Pratchett, 2004].

Перенос из высоких сфер сенсориума в низкие: а) слуховой $\rightarrow$ тактильный (4 сочетания, 0,6 \%): “audible texture” («слышимая текстура») [Ibid.]; б) зрительный $\rightarrow$ тактильный ( 5 сочетаний, $0,75 \%$ ): "Moist dimly felt the jolt” ( «Мойст тускло почувствовал толчок») [Ibid.]; в) слуховой $\rightarrow$ вкусовой (0 сочетаний); г) зрительный $\rightarrow$ вкусовой (0 сочетаний); д) слуховой $\rightarrow$ ольфакторный (1 сочетание, $0,15 \%$ ): "It was the smell... it meant warmth, and silence..." («Это был запах... он значил теплоту и тишину») [Pratchett, 2003]; е) зрительный $\rightarrow$ ольфакторный (9 сочетаний, 1,4 \%): “a stink that illumines” («вонь, которая светится») [Pratchett, 2013a].

2. Перенос в рамках высокой или низкой сфер сенсориума - низкая степень маркированости или ее отсутствие. Приведем примеры переносов в рамках высокой сферы: а) зрительный $\rightarrow$ слуховой (261 сочетание, 39,4 \%): "the tiny noises of gold" («маленькие шумы золота») [Pratchett, 2013b]; б) слуховой $\rightarrow$ зрительный (16 сочетаний, 2,4 \%): "faint noises in the beams" («тусклье шумы в лучах») [Pratchett, 2010].

Перенос в рамках низкой сферы сенсориума: а) тактильный $\rightarrow$ вкусовой (0 сочетаний); б) тактильный $\rightarrow$ ольфакторный (15 сочетаний, 2,3 \%): "sharp and reassuring smells" («ocmpые и убедительные запахи») [Pratchett, 2013а]; в) ольфакторный $\rightarrow$ тактильный (1 сочетание, 0,15 \%): "It was a stalemate, so stale as to be stinking” («Это была патовая ситуация, настолько черствая, будто воняет») [Ibid.]; г) ольфакторный $\rightarrow$ вкусовой (1 сочетание, 0,15 \%): "it [tin] tasted like the smell of snow" («на вкус [олово] было как запах снега») [Pratchett, 2003]; д) вкусовой $\rightarrow$ тактильный (0 сочетаний); е) вкусовой $\rightarrow$ ольфакторный (5 сочетаний, 0,75 \%): “The sour, salty smell” («Кисльй, соленый запах») [Pratchett, 2004].

Как показывает анализ, в исследуемых текстах лексикализованные сочетания, как правило, не получают толкования и не уточняются автором (344 исследуемых синестетических сочетания, 52 \%). Приведем ряд примеров лексикализованных синестетических сочетаний:

Before Rincewind could stop him the dragonrider had leapt from the creature's back to land on the platform, where he stood grinning at the wizard's discomfiture. There was a small expressive sound made by a number of crossbows being cocked [Pratchett, 2013b]

(«Прежде чем Ринсвинд успел что-то предпринять, К!сдра соскочил со спины дракона на платформу и, развернувшись, ухмыльнулся при виде замешательства волшебника. В воздухе пронесся тихий выразительный звук [букв. "маленький выразительной звук”], издаваемый множеством взводимых арбалетов» [Пратчетт, 2008]). 
Синестетический перенос в сочетании “small expressive sound”, представленном метафорой с адъективными атрибутами, происходит в границах высших сенсорных сфер: зрение - small 'маленький' и слух - sound 'звук'. Как можно видеть, эпитет small 'маленький' автором прямо не уточняется; сочетание "small sound" знакомо представителям английской лингвокультуры, оно не требует задействования дополнительных интеллектуальных ресурсов для интерпретации, что указывает на отсутствие у этого сочетания когнитивной маркированности.

"Every night I come out here and look down", he finished "and I never jump. Courage is hard to come by, here on the Edge". Rincewind began to crawl determinedly towards the shack. He gave a little scream as the troll picked him up, not unkindly, and set him on his feet [Pratchett, 2013b]

(«“Каждую ночь я выхожу сюда и смотрю вниз. Но пока что так и не прыгнул. Здесь, на Краю, трудно найти в себе мужество”. Ринсвинд решительно пополз в сторону хижины. Через несколько мгновений у него вырвался тихий вскрик [букв. “небольшой вопль”] - это тролль, не без доброжелательности, подхватил его и поставил на ноги» [Пратчетт, 2008]).

Как и в предыдущем примере, декодирование синестетического сочетания слов "little scream", представленного эпитетом, не требует многочисленных пояснений, оно закреплено в примерах употребления в английских толковых словарях. Находясь в пределах высших сфер восприятия (зрение - слух) адъективный эпитет little 'маленький', выступающий модусом-источником, сенсорно не отдален от ядра синестетического сочетания слов, выступающего модусом-целью. Соответственно, два этих параметра (отсутствие пояснений и малая дистанция между модусами) указывают на отсутствие когнитивной маркированности у синестетического сочетания.

Кроме лексикализованных синестетических сочетаний в исследуемых текстах встречаются «оживленные» автором лексикализованные сочетания (173 исследуемых синестетических сочетания, 26 \%). Используя пояснения, писатель увеличивает степень когнитивной маркированности, «оживляя» знакомые читателю стертые, лексикализованные сочетания. Приведем ряд примеров «оживленных» автором лексикализованных синестетических сочетаний.

The guard glanced down the deserted street, and now caught the glimmer of moonlight on something lying in the mud a few yards away. He picked it up. The lunar light gleamed on gold, and his intake of breath was almost loud enough to echo down the alleyway. There was a slight sound again, and another coin rolled into the gutter on the other side of the street [Pratchett, 2013b]

(«Охранник посмотрел на пустынную улицу и заметил, что в нескольких ярдах от него в грязи что-то блеснуло. Он поднял загадочный кругляш. Свет луны еще раз отразился от золота, и судорожный вдох охранника эхом разлетелся по безлюдному переулку. Загадочный звук [букв. “легкий звук"] повторился, и в канаву на другой стороне улицы покатилась вторая монета» [Пратчетт, 2008]).

В метафорическом сочетании слов "slight sound" перенос значения происходит от низкой сферы восприятия - осязания (slight 'легкий') к высокой 
сфере - слуху (sound 'звук'). Отдаленность модуса-источника и модуса-цели создают определенный запоминающийся образ, в котором автор уточняет тип звука, используя косвенные контекстуальные пояснения - это звук падающей монеты. Автором также используется прием антитезы: звук, производимый охранником при вдохе и представленный эпитетом loud 'громкий', противопоставляется звуку, представленному эпитетом slight 'легкий', что позволяет охарактеризовать последний как негромкий и тихий звук.

Death, insofar as it was possible in a face with no movable features, looked surprised. RINCEWIND? Death said, in tones as deep and heavy as the slamming of leaden doors, far underground [Pratchett, 2013b]

(«Смерть, лицо которого навсегда застыло в мрачной маске, также выглядел удивленным. РИНСВИНД? - уточнил он голосом низким и тяжельм [букв. “тоном столь глубоким и тяжелым”], словно подземный грохот захлопывающихся свинцовых дверей» [Пратчетт, 2008]).

Синестетический перенос в гиперболизированном синтаксическом эпитете "in tones as deep and heavy as the slamming of leaden doors, far underground" осуществляется как от низкой сферы восприятия (осязание - heavy 'тяжелый’) к высокой (слух - tones ‘тон’), так и в пределах высших сфер сенсориума (зрение - deеp ‘глубокий’ и слух - tones ‘тон’). Лексикализованная метафора “deep tones”, отраженная в словарях, дополняется авторской метафорой “heavy tones”. Для конкретизации синестетического сочетания слов “in tones as deep and heavy” автор сравнивает выражаемый этим сочетанием тип звучания со звуками «хлопанья свинцовыми дверьми глубоко под землей». Помимо контекстуального уточнения, писатель изменяет графическое начертание текста с помощью графона: произнесение имени главного героя RINCEWIND представлено заглавными буквами, что привлекает внимание читателя и служит способом детализации синестетического сочетания слов (добавление характеристик громкого звучания).

В следующем примере синестетические сочетания слов представлены лексикализованными метафорами:

"Susurrus"... according to her grandmother's dictionary, it meant "a low soft sound, as of whispering or muttering". Tiffany liked the taste of the word. It made her think of mysterious people in long cloaks whispering important secrets behind a door: susurrususssurrusss [Pratchett, 2010]

(«“Сусуррус”... В Бабушкином словаре говорилось, что это значит “мягкий, негромкий звук [букв. “низкий мягкий звук”], похожий на шепот или тихое бормотание”. Тиффани нравился вкус этого слова на языке. Ей приходили на ум таинственные люди в длинных плащах - шепчутся о важных секретах за дверью...» [Пратчетт]).

В данном примере “a low soft sound” - метафора с адъективными атрибутами, "the taste of the word” - метафора с адъюнктивным (подчинительным) существительным; перенос значения происходит от низких сфер восприятия - осязания (soft) и вкуса (taste) к высокой сфере - слуху (sound); в сочетании "low sound" 
перенос осуществляется в рамках высших сфер сенсориума (зрение и слух). Единый образ, заложенный в эти синестетические сочетания слов, достаточно непросто полностью интерпретировать и правильно понять. Для преодоления неясности и уточнения характеристик описываемого звука автор использует технику сравнения: “as of whispering or muttering” («похожий на шепот или тихое бормотание»), а более точному пониманию способствует контекст в целом: "It made her think of mysterious people in long cloaks whispering important secrets behind a door" («Он заставлял ее думать о загадочных людях в длинных плащах, о людях, которые шепчутся о важных секретах за дверью»). Взятые отдельно, лексикализованные синестетические сочетания “low sound”, "soft sound”, "taste of the word” когнитивно не маркированы. Но эти же сочетания, взятые как составные части единой целостной развернутой авторской метафоры, лишаются былой стертости, «оживают» благодаря когнитивной маркированности.

Нелексикализованные синестетические сочетания являются новыми, «свежими» (132 исследуемых синестетических сочетания, 20 \%); они отражают авторское мировосприятие. В подавляющем большинстве случаев нелексикализованные синестетические сочетания сопровождаются различными эпитетами, большим количеством пояснений и уточнений, что упрощает понимание таких необычных сочетаний. Приведем ряд примеров авторских синестетических сочетаний:

But she thought there should be a word meaning "a word that sounds like the noise a thing would make if that thing made a noise even though, actually, it doesn't, but would if it did". Glint, for example. If light made a noise as it reflected off a distant window, it'd go "glint!" And the light of tinsel, all those little glints chiming together, would make a noise like "glitterglitter". "Gleam" was a clean, smooth noise from a surface that intended to shine all day. And "glisten" was the soft, almost greasy sound of something rich and oily [Pratchett, 2010]

(«Но Тиффани думала, что должно еще обязательно быть название для слов, которые звучат как то, что на самом деле не звучит. Но если бы оно зазвучало, то именно так. Блик, например. Если бы луч света мягко оттолкнулся от дальнего окна, отразился от стекла, издав звук, это было бы “блик!”. А на мишуре из фольги эти же звуки сливаются в хор: “блики-блики-блики”. “Блистание” - звук широкой, зеркальной глади, которая может ровно сиять весь день. А “блеск” - что-то мягкое, густое, маслянистое» [Пратчетт]).

Развернутая синестетическая метафора, полностью раскрывающая образ в пяти предложениях, представляет собой конвергенцию тактильного (эпитеты smooth, soft и oily), вкусового (эпитет greasy), слухового (эпитеты noise, chimming и sound) модусов перцепции со зрительным перцептивным модусом (эпитеты light, glint, gleam и glisten). Синестетический перенос осуществляется как из низких сфер сенсориума (осязание и вкус) в высокую сферу (зрение), так и в рамках высших сфер сенсориума (слух и зрение). Многочисленные контекстуальные пояснения дают возможность лучше представить и точнее визуализировать авторскую метафору: шум света, glint! (блик!), представляет собой отражение луча света от дальнего окна, glitterglitter - это хор звуков 
на мишуре, gleam - «звук широкой, зеркальной глади, которая может ровно сиять весь день». Когнитивная маркированность лексемы glint! и окказионального слова glitterglitter придает номинации синестетического восприятия особую эмоциональность и выразительность, способствуя фокусированию внимания читателя на описываемых событиях.

Silence covered Tiffany, and drew her into itself. The silence smelled of sheep, and turpentine, and tobacco [Pratchett, 2010]

(«Молчание укрыло и укутало Тиффани. Молчание пахло овцами, скипидаром и табаком [букв. “Тишина покрыла... тишина пахла...”]» [Пратчетт]).

В составной синестетической метафоре "Silence covered... The silence smelled of sheep, and turpentine, and tobacco" осуществляется синестетический перенос из низких сфер сенсориума covered (осязание) и smelled (обоняние) - в наивысшую (слух) (в нашем случае - отсутствие звучания, которое принадлежит слуховому модусу перцепции). Контекстуальные сведения способствуют интерпретации авторской метафоры: предложение "Silence covered Tiffany, and drew her into itself” («Тишина укрыла Тиффани и погрузила в себя») уточняет, что тишина сенсорно напомнила героине о былых ощущениях - в тексте многократно упоминается тихая и спокойная обстановка в доме бабушки Тиффани, где пахло «овцами, скипидаром и табаком». Таким образом, бо́льшая отдаленность перцептивных модусов может свидетельствовать о бо́льшей степени когнитивной маркированности в авторском, нелексикализованном синестетическом сочетании слов. Увеличению степени маркированности (читателю нужно больше объяснений) также способствует привлечение большего объема контекстуальных данных. Большое количество объяснений (не только конкретного синестетического сочетания, но и ситуации в целом), сопровождающих синестетическое сочетание, позволяет сделать вывод о том, что это сочетание более когнитивно маркировано.

В некоторых случаях авторские («свежие») синестетические сочетания могут не поясняться и не уточняться (13 исследуемых синестетических сочетаний, 2 \%), например:

"There was darkness everywhere, bitter and starless" [Pratchett, 2010]

(«Тьма была повсюду, лютая и беззвездная [букв. “тьма... была горькая...”]» [Пратчетт]).

Синестетический перенос в сочетании “darkness... bitter”, представленном структурно обособленной метафорой, осуществляется из низкой сферы восприятия (вкус - bitter 'горький') в высокую (зрение - darkness 'тьма'). Данное синестетическое сочетание не получает интерпретации, не маркируется. Тем не менее, синестетическое сочетание “bitter darkness” семантически осложнено, читатель вынужден самостоятельно представить себе и распознать дополнительные перцептивные характеристики отсутствия света, прилагая определенные ментальные усилия. Соответственно, когнитивно немаркированное для автора 
синестетическое сочетание может являться когнитивно маркированным для читателя. 2010].

She cupped it in her hands to keep the raindrops out, and listened to her eyes [Pratchett,

(«Сложила над блюдцем ладони чашечкой, чтобы прикрыть от дождя, и принялась чуять глазами [букв. “слушала глазами”]» [Пратчетт]).

В данном примере синестетическое сочетание слов представлено глагольной метафорой “listened to her eyes” («слушала глазами»), в которой перенос значения происходит в границах высших сенсорных сфер (слух - listen 'слушать' и зрение - eyes 'глаза'). Благодаря данному сочетанию передается высокая степень эмоциональности и напряженности описываемых событий, демонстрируется серьезность и максимальная сосредоточенность героини на процессе восприятия. Отсутствие уточнений подобного необычного способа восприятия позволяет говорить о немаркированности синестетического сочетания для автора. Для читателя такое синестетическое сочетание будет стилистически ярким и необычным.

Проведенное исследование позволяет сделать следующие выводы.

1. В рассматриваемых текстах Терри Пратчетта приемом сплошной выборки было отобрано 662 синестетических сочетания. Из них 344 синестетических сочетания являются лексикализованными сочетаниями, когнитивно не маркированными; 173 синестетических сочетания обладают низкой степенью когнитивной маркированности, «оживлены», переосмыслены автором; 145 синестетических сочетаний обладают высокой степенью когнитивной маркированности - это авторские новые синестетические сочетания.

2. В 363 синестетических сочетаниях (что составляет 55 \% от общего числа) осуществляется перенос из низких сфер сенсориума в высокие или из высоких в низкие. Дистанция между перцептивными модусами в этих сочетаниях высокая, что делает описываемый автором феномен необычнее и семантически сложнее, более когнитивно маркированным.

В 299 синестетических сочетаниях (что составляет 45 \% от общего числа) интермодальный перенос осуществляется в рамках только высокой или только низкой сфер сенсориума. В близких сферах сенсориума синестетические сочетания слов обладают меньшей степенью когнитивной маркированности.

3. Наличие в тексте различных пояснений и уточнений синестетических сочетаний способствует повышению степени когнитивной маркированности этих сочетаний. Расширение контекста и использование автором дополнительных стилистических средств в синестетических сочетаниях (сравнение, гипербола, антитеза, графическое выделение) усложняют понимание описываемых объектов и явлений.

4. Применение параметра когнитивной маркированности позволило выявить следующие модели синестетических сочетаний:

а) немаркированные лексикализованные сочетания; 
б) маркированные («оживленные») лексикализованные сочетания;

в) маркированные авторские («свежие») сочетания;

г) немаркированные авторские («свежие») сочетания.

Лексикализованные синестетические сочетания зафиксированы в словарях и могут обладать разной степенью когнитивной маркированности: немаркированные лексикализованные сочетания - это синестетические сочетания, закрепленные в языке, при которых отсутствуют пояснения и которые отражают небольшую сенсорную дистанцию между модусами перцепции; маркированные («оживленные») лексикализованные сочетания - это синестетические сочетания, закрепленные в языке, при которых имеются уточнения, и которые отражают бо́льшую сенсорную дистанцию между перцептивными модусами, что приводит к увеличению степени когнитивной маркированности и способствует «оживлению» утраченной образности.

Авторские («свежие») сочетания являются семантически осложненными. Они, как правило, сопровождаются значительным объемом контекстуальных уточнений, сенсорная дистанция между модусами перцепции этих сочетаний значительна. Наиболее частотными являются переносы из сферы осязания в зрительную и слуховую сферы. Большое количество контекстуальных уточнений свидетельствует о высокой степени когнитивной маркированности таких сочетаний.

Существуют и немаркированные авторские синестетические сочетания, в которых отсутствуют пояснения автора. Отсутствие пояснений и уточнений, с одной стороны, свидетельствует о немаркированности таких сочетаний для автора, с другой стороны, позволяет утверждать, что для читателя подобные незнакомые семантически осложненные сочетания потребуют дополнительных ментальных затрат. Возможное несовпадение степени маркированности для автора и для потенциального читателя может указывать на их различное восприятие.

\section{Источники}

Пратчетm T. Вольные мальцы / пер. с англ. Staff [Электронный ресурс]. URL: http://www.ereading.by/book.php?book=90386 (дата обращения: 20.03.2017).

Пратчетт Т. Цвет волшебства / пер. с англ. И. Кравцовой, под ред. А. Жикаренцева. М. : Эксмо, 2008.

Pratchett T. The Wee Free Men, 2003 [Electronic resource]. URL: https://royallib.com/get/rtf/ Pratchett_Terry/The_Wee_Free_Men.zip (accessed: 20.01.2018).

Pratchett T. Going Postal, $200 \overline{4}$ [Electronic resource]. URL: https://royallib.com/get/rtf/Pratchett_ Terence/Going_Postal.zip (accessed: 20.01.2018).

Pratchett T. Wintersmith. 2006 [Electronic resource]. URL: https://royallib.com/get/rtf/Pratchett_ Terry/Wintersmith.zip (accessed: 20.01.2018).

Pratchett T. Making Money, 2007 [Electronic resource]. URL: https://royallib.com/get/rtf/ Pratchett_Terry/Making_Money.zip (accessed: 20.01.2018).

Pratchett T. I Shall Wear Midnight, 2010 [Electronic resource]. URL: https://royallib.com/get/ rtf/Pratchett_Terry/I_Shall_Wear_Midnight.zip (accessed: 20.01.2018). 
Pratchett T. Raising Steam, 2013a [Electronic resource]. URL: https://royallib.com/get/rtf/ Pratchett_Terry/raising_steam.zip (accessed: 20.01.2018).

Pratchett T. The Colour of Magic. New York : HarperColins Publishers : Reissue edition, 2013b.

\section{Исследования}

Арутюнова Н. Д. Метафора и дискурс // Теория метафоры : сб. : пер. с анг., фр., нем., исп., польск. яз. / сост. Н. Д. Арутюнова ; общ. ред. Н. Д. Арутюновой и М. А. Журинской. М. : Прогресс, 1990. С. 5-32.

Бардовская А. И. Средства номинации синестетических соощущений (на материале английских и русских художественных текстов) : дис. ... канд. филол. наук / Твер. гос. ун-т. Тверь, 2005.

Капанова А. А. Синестетическое использование имен прилагательных в современном французском языке : дис. ... канд. филол. наук. М., 1984.

Карпенко Л. А. Краткий психологический словарь / под общ. ред. А. В. Петровского, под общ. ред. М. Г. Ярошевского, ред.-сост. Л. А. Карпенко. 2-е изд., расш., испр. и доп. Ростов н/Д : Феникс, 1998.

Касавин И. Т. Энциклопедия эпистемологии и философии науки. М. : Канон+ : Реабилитация, 2009.

Кибрик А. Е. Когнитивный подход к языку // Компьютеры, мозг, познание: успехи когнитивных наук / ред. Б. М. Величковский, В. Д. Соловьев. М. : Наука, 2008. С. 202-232.

Кривенкова И. А. Синестезия в языке художественной прозы М. А. Шолохова : дис. ... канд. филол. наук. М., 2006.

Лаврова С. Ю. Перцептивный образ субъекта восприятия в аспекте оценочного модуса // Лингвистическое наследие Шарля Балли в XXI веке : материалы Междунар. науч.-практ. конф., 5-7 октября 2009 года / [отв. ред. Г. В. Елизарова]. СПб. : РГПУ, 2009. С. 47-56.

Лурия А. Р. Психология ощущения и восприятия. М. : Изд. МГУ, 1971.

Мерзлякова A. X. Семантическое варьирование прилагательных в поле «Восприятие» [Электронный ресурс] // Вестн. СПбГУ. 2003. Сер. 2. Вып. 4 (№ 26). URL: https://elibrary.ru/ download/elibrary_21115459_34571969.pdf (дата обращения: 16.10.2017).

Молодкина Ю. Н. Синестетическая метафора запаха : дис. ... канд. филол. наук / Курск. гос. ун-т. Курск, 2010.

Рубинштейн С. Л. Основы общей психологии. СПб. : Питер, 2000.

Рузин И. Г. Когнитивные стратегии именования: модусы перцепции (зрение, слух, осязание, обоняние, вкус) и их выражение в языке // Вопр. языкознания. 1994. № 6. С. 79-99.

Степанян Т. Р. Синестетические метафоры русского языка (прилагательные чувственного восприятия) : дис. ... канд. филол. наук / Ин-т рус. яз. АН СССР. М., 1987.

Филиппова Г. Н. Узуальная и окказиональная синестезия в современном немецком языке : дис. ... канд. филол. наук / Нижегор. гос. лингв. ун-т им. Н. А. Добролюбова. Н. Новгород, 2010.

Цоллингер Г. Биологические аспекты цветовой лексики // Красота и мозг. Биологические аспекты эстетики : пер. с англ. / под ред. И. Ренчлера, Б. Херцбергер, Д. Эпстайна. М. : Мир, 1995. С. $156-173$.

Яницкая Н. И. Адъективная синестезия в английской и русской поэзии романтизма : дис. ... канд. филол. наук. М., 2010.

GreenbergJ. Language universals: with special reference to feature hierarchies / by J. H. Greenberg; with a preface by M. Haspelmath. The Hague : Mouton de Gruyter, 2005.

\section{References}

Arutyunova, N. D. (1990). Metafora i diskurs [Metaphor and Discourse]. In N. D. Arutyunova, \& M. A. Zhurinskaya (Eds.), Teoriia metafory [Metaphor Theory] (pp. 5-32). Moscow: Progress. (In Russian) 
Bardovskaya, A. I. (2005). Sredstva nominatsii sinesteticheskikh sooshchushchenii (na materiale angliiskikh i russkikh khudozhestvennykh tekstov) [Means for the Nomination of Synaesthetic Sensations (with Reference to English and Russian Fiction Texts)] (doctoral dissertation abstract). Tver. (In Russian)

Filippova, G. N. (2010). Uzual'naia i okkazional'naia sinesteziia v sovremennom nemetskom iazyke [Usual and Occasional Synaesthesia in the Modern German Language] (doctoral dissertation abstract). Nizhny Novgorod. (In Russian)

Greenberg, J. (2005). Language Universals: With Special Reference to Feature Hierarchies. The Hague: Mouton de Gruyter.

Kapanova, A. A. (1984). Sinesteticheskoe ispol'zovanie imen prilagatel'nykh v sovremennom frantsuzskom iazyke [The Synaesthetic Usage of Adjectives in Modern French] (doctoral dissertation abstract). Moscow. (In Russian)

Karpenko, L. A. (1998). Kratkii psikhologicheskii slovar' [Short Psychological Dictionary]. Rostovon-Don: Feniks. (In Russian)

Kasavin, I. T. (2009). Entsiklopediia epistemologii i filosofii nauki [Encyclopedia of the Epistemology and Philosophy of Science]. Moscow: Kanon+; Reabilitatsiia. (In Russian)

Kibrik, A. E. (2008). Kognitivnyi podkhod k iazyku [Cognitive Approach to Language]. In Velichkovsky, B. M., \& Solovyev, V. D. (Ed.), Komp'iutery, mozg, poznanie: uspekhi kognitivnykh nauk [Computers, Brain, Cognition: Advances of Cognitive Sciences] (pp. 202-232). Moscow: Nauka. (In Russian)

Krivenkova, I. A. (2006). Sinesteziia v iazyke khudozhestvennoi prozy M. A. Sholokhova [Synaesthesia in the Language of M. A. Sholokhov's Prose Fiction] (doctoral dissertation abstract). Moscow. (In Russian)

Lavrova, S. Yu. (2009). Pertseptivnyi obraz sub”ekta vospriiatiia v aspekte otsenochnogo modusa [The Perceptual Image of the Perception Subject in the Aspect of Evaluation Mode]. In G. V. Elizarova (Ed.), Lingvisticheskoe nasledie Sharlia Balli v XXI veke [The Linguistic Heritage of Charles Bally in the $21^{\text {st }}$ Century] (pp. 47-56). St Petersburg: RGPU. (In Russian)

Luria, A. R. (1971). Psikhologiia oshchushcheniia i vospriiatiia [The Psychology of Sensation and Perception]. Moscow: MGU. (In Russian)

Merzlyakova, A. Kh. (2003). Semanticheskoe var'irovanie prilagatel'nykh v pole "Vospriiatie" [Semantic Change of Adjectives in the "Perception" Field]. Vestnik SPbGU. Seria 2, 4 (26). Retrieved from https://elibrary.ru/download/elibrary_21115459_34571969.pdf. (In Russian)

Molodkina, Yu. N. (2010). Sinesteticheskaia metafora zapakha [The Synaesthetic Metaphor of Smell] (doctoral dissertation abstract). Kursk. (In Russian)

Rubinstein, S. L. (2000). Osnovy obshchei psikhologii [Fundamentals of General Psychology]. St Petersburg: Piter. (In Russian)

Ruzin, I. G. (1994). Kognitivnye strategii imenovaniia: modusy pertseptsii (zrenie, slukh, osiazanie, obonianie, vkus) i ikh vyrazhenie v iazyke [Cognitive Naming Strategy: Modes of Perception (Vision, Hearing, Touch, Smell, Taste) and their Expression in Language]. Voprosy jazykoznanija, 6, 79-99. (In Russian)

Stepanyan, T. R. (1987). Sinesteticheskie metafory russkogo iazyka (prilagatel'nye chuvstvennogo vospriiatiia) [Synaesthetic Metaphors in the Russian Language (Adjectives of Sense Perception)] (doctoral dissertation abstract). Moscow. (In Russian)

Yanitskaia, N. I. (2010). Ad"ektivnaia sinesteziia v angliiskoi i russkoi poezii romantizma [Adjectival Synaesthesia in the English and Russian Poetry of Romanticism] (doctoral dissertation abstract). Moscow. (In Russian)

Zollinger, G. (1995). Biologicheskie aspekty tsvetovoi leksiki [The Biological Aspects of the Colour Vocabulary]. In I. Rentschler, B. Herzberger, \& D. Epstain (Eds.), Krasota i mozg. Biologicheskie aspekty estetiki [Beauty and the Brain. Biological Aspects of Aesthetics] (pp. 156-173). Moscow: Mir. (In Russian) 


\section{Баева Наталья Александровна}

кандидат филологических наук, доцент кафедры английской филологии

Кемеровский государственный университет

650000, Кемерово, ул. Красная, 6

E-mail: baeva-angl@rambler.ru

Фомин Анатолий Анатольевич

аспирант кафедры английской филологии

Кемеровский государственный

университет

650000, Кемерово, ул. Красная, 6

E-mail: anatoly.formean@gmail.com
Baeva, Natalia Aleksandrovna

PhD (Philology), Associate Professor

Department of English Philology

Kemerovo State University

6, Krasnaya Str., 650000 Kemerovo, Russia

Email: baeva-angl@rambler.ru

Researcher ID: O-1200-2016

Fomin, Anatoly Anatolyevich

PhD Student

Department of English Philology

Kemerovo State University

6, Krasnaya Str., 650000 Kemerovo, Russia

Email: anatoly.formean@gmail.com 